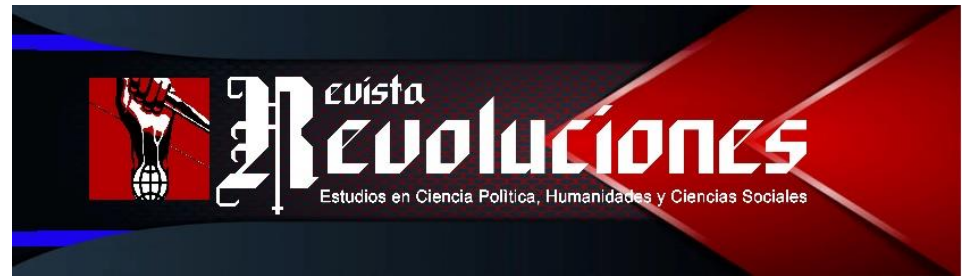

\title{
MICAELA BASTIDAS: APUNTES SOBRE SU CONFLICTO DE ROLES
}

\author{
Micaela Bastidas: apuntes on her role conflicto
}

\author{
Amparo Kanashiro ${ }^{1}$ \\ UNIVERSIDAD NACIONAL HERMILIO VALDIZÁN \\ PERÚ \\ amparokanashirosantillan@gmail.com.pe \\ https://orcid.org/oooo-0001-7029-2588
}

DOI: https://doi.org/10.35622/j.rr.2021.05.007

Recibido: 10-VI-2021 / Aceptado: 20-VII-2021 / Actualizado: 29-VII-2021

\begin{abstract}
Resumen
En el marco de la conmemoración del Bicentenario de la Independencia del Perú, el artículo tiene como propósito contextualizar los roles que desempeñó Micaela Bastidas, a través de una recopilación de cartas escritas por los escribanos de Micaela Bastidas, quienes plasmaban sus ideas y solicitudes de manera escrita, en medio de la rebelión entre 1780 a 1781 . Así mismo se examina parte de sus respuestas frente al interrogatorio del proceso penal al que fue sometido por su participación en el movimiento rebelde. Este contexto, nos traslada a una empatía histórica con Micaela, ya que tuvo que lidiar entre su rol de madre y heroína, desde una perspectiva de género. La mayoría de cartas corresponde a los esfuerzos que Micaela hizo multiplicando sus roles, como también los esfuerzos y compromisos que hacía su esposo, hijos y el resto de su familia para vencer a las tropas realistas. Micaela rompió el esquema de un sujeto pasivo y relegada al espacio privado para ser protagonista del espacio público pese al conflicto de roles que asumió.
\end{abstract}

Palabras Clave: Conflicto de roles, heroína, madre, Micaela Bastidas, opresión.

\begin{abstract}
In the framework of the commemoration of the Bicentennial of the Independence of Peru, the article aims to contextualize the roles played by Micaela Bastidas, through a compilation of letters written by the notaries of Micaela Bastidas, who reflected their ideas and requests in a written, in the midst of the rebellion between 1780 and 1781 . Likewise, part of his responses to the interrogation of the criminal process to which he was subjected for his participation in the rebel movement is examined. This context takes us to a historical empathy with Micaela, since she had to deal between her role as mother and heroine from a gender perspective. Most of the letters correspond to the efforts that Micaela made multiplying her roles, as well as the efforts and commitments made by her husband, children and the rest of her family to defeat the royalist troops. Micaela broke the scheme of a passive subject and relegated to the private space to be the protagonist of the public space despite the conflict of roles that she assumed.
\end{abstract}

${ }^{1}$ Investigadora de la Universidad Nacional Hermilio Valdizán, Perú. 
Keyword: Role conflict, heroine, mother, Micaela Bastidas, oppression.

\section{INTRODUCCIÓN}

El enfoque de género ha conllevado a analizar los diferentes y múltiples roles asumidos por Micaela Bastidas en el contexto de la rebelión tupacamarista, la historiografía ha resaltado su participación activa, a partir de ello se extiende la mirada hacia los conflictos de roles que ha experimentado entre su rol de madre y heroína en el proceso de rebelión.

Desde la llegada de los españoles las mujeres estaban supeditadas al sistema patriarcal, sistema que les había circundado pasivamente en su papel doméstico, pero ese esquema se rompió cuando las mujeres como Micaela por sentido común de búsqueda de justicia, protagonizaron activamente su lucha contra el sistema opresivo colonial, propio de la esfera pública (excesivos tributos y repartos, abuso de los corregidores, trabajos desmedidos en las mitas, entre otros) que afectaban a la familia de Micaela y a las comunidades aledañas de Cusco. Años antes de 1780 por ese motivo surgieron una serie de alzamientos y revueltas en Cusco.

Scarlett determinó el carácter y la composición social de las revueltas anti fiscales en el Cusco en la década de 1770 a 1780. Scarlett (como se citó en Angles, 2004). En Quechualla se alzaron contra el corregidor por repartos excesivos en 1771, en Urubamba se alzaron contra el corregidor Don Pedro Lefedal y Melo por abusos en los repartos en 1777, en Chumbivilcas mataron a su corregidor en 1776. Cusco comprendía 14 provincias y 133 curatos, era común entre las familias la disconformidad y el sentimiento de injusticia de las autoridades.

El rol de Micaela Bastidas en la esfera pública no fue valorado, pero sí perceptible, porque ensordeció a las autoridades y al bando español, con su valentía, superioridad, protagonismo, órdenes, lealtad, habilidades y destrezas en el campo administrativo y político de la rebelión, lamentablemente su protagonismo no tuvo continuidad, se apagó tan pronto debido a los escarmientos y represalias por parte de las autoridades españolas. Para que no acrecentará y ejemplificara el número de mujeres contra la opresión, convirtieron en una escena, los castigos más crueles contra Micaela, y otras mujeres como Tito Tomasa Condemayta, Cecilia Túpac Amaru, Gregoria Apaza, Bartolina Sisa.

Charles Walker, en su repaso de la historiografía de Túpac Amaru, juzgó el papel de españoles considerando que buscaron desaparecer la memoria de los rebeldes, no solo los mataron cruelmente y públicamente sino que colgaron parte de sus cuerpos en diferentes pueblos como evidencia de que era un peligro la sublevación. Sus nombres no se escucharon durante mucho tiempo en Cusco y durante las décadas posteriores debido al temor no llegaron a ser símbolos en las largas luchas por la Independencia de 1808 a 1824 (Walker, 2021). 
Para el balance historiográfico sobre el rol de Micaela Bastidas en la emancipación se examinó trabajos como el de Sara Beatriz, Micaela Bastidas y la insurrección de 1780, cuyo propósito es resaltar a Micaela Bastidas como la representación femenina que deslumbró con sus capacidades administrativas y políticas en medio de una agitación social, de alzamientos y vejaciones que sufrían los indios, asimismo como una mujer que movilizó a la población indígena a favor de la causa, del mismo modo Edgar Montiel en su artículo Micaela, una herida en la memoria. La mujer relegada en el discurso histórico destaca el liderazgo de Micaela como propio, autónomo y estratégico, pero cuestiona a la historiografía que solo le había idealizado como la esposa de José Gabriel Túpac Amaru.

Por otro lado, Mary G. Berg en su trabajo Micaela Bastidas en su época, resalta los atributos de inspiración y persuasión de Micaela Bastidas, atributos que manifestaba para garantizar lealtad y participación de los pueblos indígenas, como también reconoce la labor doméstica que realizó desde muy joven.

En cuanto a su rol de género, Sebastián Salazar Rocuant en su tesis, tres mujeres de independencia, tres aportes distintos: la construcción del sujeto histórico femenino en la sociedad tradicional, considera que el papel de Micaela traspasó la esfera privada a la esfera pública, por haber luchado junto con su marido por la misma causa emancipatoria, ambos con un solo ideal en una sociedad tradicional. Entendiéndose que Túpac Amaru respetó y valoró su rol, sin embargo en los trabajos de Scarlett O'Phelan Godoy, La rebelión de Túpac Amaru, organización interna dirigencia y alianza sin minimizar el papel de Micaela Bastidas considera que la declaración de Micaela de que "su esposo Túpac Amaru alguna vez le maltrató por no hacerle caso" fue una declaración que dio para desligarse de las responsabilidades que tenía con su esposo, entendiéndose ello como quería hacer las cosas con autonomía sin la necesidad de compartir el rol con su esposo.

Se ha analizado también a Alfonsina Barrionuevo quien con mucho acierto narrativo reconstruyó pasajes de Micaela Bastidas resaltando su papel en la independencia. En cuanto al conflicto de roles se ha analizado la postura de autores como Johana Garay Becerra y Francisco Fuster García quienes cuestionan la invisibilidad de las mujeres en la historia tradicional.

Asimismo, se ha examinado las cartas redactadas e interpretadas por los escribientes Mariano de la Banda, Felipe Miguel Bermúdez, Diego Ortigosa, José Esteban Escarcena, Francisco Cisneros, Manuel Galeguillo y Diego Berdejo, más autores que se detallan en el desarrollo entre ellos Carlos Daniel Valcarcel, Boleslao Lewin, Claudia Luna entre otros.

Una inquietante problematización del trabajo, son las limitadas fuentes sobre Micaela anterior a la rebelión, la mayoría de las investigaciones se centran a partir del matrimonio con Túpac Amaru II, que data del 25 de mayo d 1760 hasta su muerte en 1781 . 
El artículo nos invita a analizar la incompatibilidad de roles de Micaela Bastidas, roles que no fue pacífico, por lo contrario, su rol de compatriota terminó sobreponiéndose a su rol de madre, porque sacrificó su vida, sacrificó el tiempo de sus hijos y su familia. Ambos roles fueron valorados por su familia y las tropas compatriotas, pero en la esfera pública su rol fue magullado.

El artículo explora la inflexión de sus roles en la coyuntura de la rebelión, esbozando sus sacrificios, preocupaciones, amor por sus hijos y por lado su compromiso, lealtad, e inmolación en el escenario de la rebelión.

\section{METODOLOGÍA}

La investigación es de tipo cualitativo, dimensión inducción, se ha centrado en examinar el rol de Micaela, como sujeto histórico, parte de su vida interna, como su perspectiva, éxitos, fracasos, esfuerzos, y sacrificios que se han evidenciado en las cartas y en las respuestas que dio en el interrogatorio que se le hizo en el proceso penal. Se ha evaluado la perspectiva de los autores y el valor de la fuente según su grado de pertinencia y confiabilidad. Su rol se ha analizado también en referencia a la esfera pública y su espacio privado que comprometía a su esposo y sus hijos.

Se ha trabajado con técnicas de análisis bibliográfico, con una evaluación del valor de las fuentes de acuerdo a su origen, propósito y contenido. Para la obtención de datos se ha trabajado con fichas bibliográficas y comparación de fuentes que precedían a la formulación final de la hipótesis. El artículo examinó fuentes descriptivas, interpretativas y analíticas con un enfoque teórico metodológico.

\section{RESULTADOS}

Micaela Bastidas representa a tantas mujeres, madres y heroínas que lucharon en el proceso de emancipación e independencia, muchas de ellas se están haciendo visibles gracias a los trabajos historiográficos regionales y locales.

Desde 1781, año en que murió Micaela Bastidas escenificando dolor que se quedó perenne en nuestra memoria, hasta la actualidad las mujeres siguen afrontando otras formas de desafíos, como el rol maternal y laboral, es evidente el conflicto en su espacio privado y en el público.

La visibilidad de las mujeres que lucharon por la causa se redujo a su familia y a los patriotas, y no perduró, debido a los escarmientos que dieron los españoles a aquellas mujeres. Como Valero (2009) señala Micaela Bastidas. [...] heroína de la libertad que, con esta rebelión, trató no sólo de liberar a su pueblo de la explotación, sino también de restablecer la tradición indígena de herencia prehispánica de participación de la mujer en la vida social y política; tradición que el sistema colonial había tratado de abolir hasta los extremos más vejatorios para la mujer indígena, víctima de todo tipo de abusos (p.65). 
La contribución de las mujeres, ha sido trascendental, aunque la historia tradicional "masculinizada" y el poder en el Perú a lo largo de la época republicana no le ha visibilizado, Al respecto Rodas (1995) señala la historia y la experiencia que ellas han acumulado son propios e intransferibles, y, si bien es cierto, que estos no son independientes de las experiencias de los hombres, tampoco se pueden explicar con la sola observación de los hombres como únicos sujetos históricos (p.48).

En la misma línea de Rodas, Varela también cuestiona que el papel de la mujer en la historia era como un papel en blanco, Varela (como se citó en Garay, 2018), "las nadie son millones en el mundo, su experiencia no tiene altavoces [...] las nadies han estado presente en la historia como sus compañeros, pero la historia se ha encargado de ocultarlas" (p. 62). Los peninsulares después de ver la capacidad de las mujeres peruanas intentaron oscurecer el "ejemplo de mujeres luchadoras, valientes, activas en las batallas".

Coincidiendo con la postura de Johana Garay Becerra, Francisco Fuster García considera que se hace necesario seguir rastreando a las mujeres para hacerlas visible en todas sus dimensiones.

Fuster (2009), refiere "Debemos hacer un intento de rastrear a las mujeres en la historia y hacerlas visibles. La historia académica y convencional, se había centrado en los espacios públicos no femeninos [...] obviando de este modo incluso el ámbito de lo doméstico (p. 249). Es así como el artículo no minimiza ninguno de sus roles por lo contrario se visibiliza ambos roles, el ámbito privado de la familia de Micaela y de las familias de su época también fue importante, porque son en esos espacios en donde se fortaleció el sentimiento de justicia y patriotismo.

\section{Micaela Bastidas entre el amor de sus hijos y su lucha contra la opresión española}

Las cartas que dictó Micaela a sus escribientes quedan como evidencia del sufrimiento y la preocupación por sus hijos en el contexto de la rebelión, su rol como madre también fue determinante porque sus hijos lucharon con convicción y lealtad contra la opresión española. Pero el amor maternal y el sufrimiento de los hijos o niños fue un papel secundario para los españoles.

Vovelle (como se citó en Carillo, 1989) refiere que la mentalidad se inscribe en el concepto más amplio de ideología, y se integra por lo que es aparentemente insignificante, que en la historia han estado hecho trizas, como el amor, la niñez, la familia, amor y sexo. Por otro lado, Bloch (como se citó en Ginzburg, 2015), señala "la historia de los sentimientos y de las ideas, que son, de entre todas las historias, las más difíciles de reconstruir y de comprender desde el interior marcan pasos importantes para comprender la historia” (p.33). Analizar a 
Micaela se sintetiza en una empatía histórica, una heroína que lucha por su familia y con su familia una historia que fue postergada y secundada en la historiografía.

Micaela Bastidas nació en 1744 y murió en 1781, se casó a los 16 años con Túpac Amaru II el 25 mayo 1760 y tuvieron 3 hijos, Hipólito que nació en 1761 en Surimana, Mariano que nació en 1762 en Tungasuca y Fernando en 1768 en Tungasuca. Sus hijos muy jóvenes formaron parte de las estrategias planteadas por sus padres y participaron activamente, es decir fueron parte de sus derrotas, triunfos, traiciones e injusticias.

Los estudios que se han realizado acerca de su instrucción señalan que no sabía escribir ni leer, pero ella abnegada apoyó a sus hijos en su educación como refiere Sara Beatriz Guardia en su artículo titulado Micaela Bastidas y la insurrección de Túpac Amaru, Guardia (2015) señala "Conformaron una pareja unida y preocupada por la educación de sus hijos, a quienes supieron transmitir el anhelo por la libertad y la justicia social. No es casual que contrataran maestros para su instrucción para evitar que estudien en el Colegio de Caciques del Cusco, orientado a preparar jóvenes sumisos a la Corona de España", educaron a sus hijos con sentimiento "patriótico" (p.6).

En las cartas que Edgar Montiel en el año 2003 compartió con la historiadora Scarlett O' Phelan Godoy, copia de la Guía en el Archivo General de la Nación, la historiadora interpretó las petacas en donde se puede apreciar algunas cosas que tenían como parte de su vida cotidiana.

"En las dos petacas que llevó consigo para su uso y el de su familia" había tres vestidos de color, tres capas, cuatro sombreros de petate, tres sombreros de jipijapa y dos de su propio uso, tres cortes de mantilla, dos faldellines, dos piezas de Bretaña; esto en términos de vestuario. Pero también aparecen algunas otras adquisiciones sorprendentes, como un astrolabio, un molinillo de café, una encomienda de libros y nada menos que una obra de Garcilaso. Esto implica que no era "probable" que Túpac Amaru hubiera leído a Garcilaso, sino que, en efecto, compró y consultó la obra del cronista mestizo" (Montiel, 2019). el mismo autor Edgar Montiel considera que la obra de Garcilaso fue comprado y consultado, se deduce que lo leían y que algún momento conversaron con su familia al respecto.

Para Micaela y su esposo debe haber sido difícil afrontar la situación, porque eran conscientes de que sus hijos también estarían en peligro, cuando Micaela expresaba "Por la libertad de mi pueblo he renunciado a todo. No veré florecer a mis hijos" (Barrionuevo, 1976, p. 4). No renunció a sus hijos, renunció los buenos momentos que deberían de disfrutar en familia por los difíciles momentos que les tocó vivir luchando contra la opresión española.

En las cartas se puede evidenciar su conflicto entre su rol de madre y los retos que asumió luchando a favor de la causa, Micaela reconoce que fue complicado liderar actividades que comprendía la rebelión, estar pendiente de las informaciones, responder cartas, coordinar las estrategias. 
La escritora cusqueña Alfonsina Barrionuevo reconstruye pasajes de la vida de Micaela Bastidas, en su libro Habla Micaela se detalla.

\begin{abstract}
Para una mujer que estuvo en su casa no es tarea sencilla mandar hombres. Lo hago porque debo atender nuestros asuntos mientras José Gabriel está ausente. Felizmente los escribientes me ayudan y así se alivia mi carga. No sé qué haría sin Mariano de la Banda, Felipe Miguel Bermúdez, Diego Ortigosa, José Esteban Escarcena, Francisco Cisneros, Manuel Galeguillo y Diego Berdejo que se alternan, a veces con mi marido y otras conmigo, en Tinta o Tungasuka, nunca había escrito tantas cartas, además de los pases porque los indios están bravos y lo viajeros no tiene pase franco. 30 de noviembre "[...] la vida de él y la mía ya no nos pertenece, así pensamos el día en qué José Gabriel comenzó a alzarse contra la opresión. Me duele haber dispuesto la vida de nuestros hijos, que correrán la misma suerte en la alegría o la desventura (Barrionuevo, 1976, p. 7).
\end{abstract}

En la cita se hace visible la expresión nostálgica de Micaela Bastidas de admitir lo difícil que era sacrificar su familia y atender los asuntos de la rebelión.

Del mismo modo desde la perspectiva de Berg (2013) señala que Micaela desde muy joven debido a las actividades que realizaba su esposo que le conducían a realizar viajes largos, durante la ausencia de su esposo, en su casa, Micaela Bastidas se habría acostumbrado muy joven no solo a mantener el hogar a sus cortos 18 años y con 2 hijos, sino el lado doméstico de los negocios de su marido.

Empoderándose del reto que asumió Micaela se abrió camino aprendiendo estrategias, empoderándose del liderazgo, conociendo a las personas con las que podía incorporar a las tropas, planificando la tarea en referencia al contexto. "su conciencia de Justicia que movía la rebelión -convicción que trasmitió a sus hijos, familiares y vecinos- y se evita en la consciencia recordar los tormentos extremos que tuvo que soportar, pues es una herida en la memoria de América” (Montiel, 2019, p. 44).

Sus hijos también estaban empoderados de las estrategias que había planteado Micaela y Túpac Amaru, como se evidencia en las cartas que interpretó la investigadora peruana Sara Guardia refiere que se dirigía a ellos en el mismo nivel al que se dirigía los combatientes, la información y el mensaje es semejante a los que se dirige a un combatiente de igual rango. Son comunicaciones de guerra, con lo preciso y necesario, no existe mención que corresponda al ámbito privado, ni siquiera de los hijos, aunque Hipólito de 19 años combatía con Tupac Amaru, y Mariano de 18 cumplía tareas de importancia. Pese al vinculo de madre e hijos, sus hijos son unos combatientes más, eran hijos de Micaela y también eran "hijos del Perú", por lo menos el tiempo que duró la rebelión de la familia "Amaru Bastidas" ella fue reconocida, temida, comentada, respetada y no necesariamente porque era "esposa de Túpac Amaru II" sino por sus propios méritos, aunque los españoles unieron fuerzas para que su nombre se ocultará, no lo lograron del todo. 
Micaela no ordenaba sentada en un lugar solo esperando las novedades del día, tanto ella como sus hijos, esposo y su familia tuvieron notables participaciones en el mismo escenario. Sostiene (Melchor de Paz citado por Sumi, 2017) no solo participó en la elaboración del plan del ataque a Cusco junto a sus hijos para ocupar Lauramarca y Paucartambo en la ejecución del corregidor Antonio Arriaga, Micaela Bastidas tuvo la mayor inteligencia en medio de la flaqueza de su sexo esforzaba las diligencias [...] cargando en su misma mantilla las balas necesarias para la guardia" (p. 25).

Micaela exigía responsabilidad, compromiso y efectividad a su esposo, como se evidencia en una carta publicada por Jornada de Estudios de Género y las mujeres en la historia del Perú (2021). "Chepe mío: tú me has de acabar de pesadumbres, pues andas muy despacio paseándote en los pueblos, y más en Yauri, tardándote dos días con grande descuido, pues los soldados tienen razón de aburrirse e irse cada uno a sus pueblos. Yo ya no tenga paciencia para aguantar todo esto, pues yo misma soy capaz de entregarme a los enemigos para que me quiten la vida, porque veo el poco anhelo con que ves este asunto tan grave que corre con detrimento de la vida de todos, y estamos en medio de los enemigos que no tenemos ahora segura la vida; y por tu causa están a pique de peligrar todos mis hijos, y los demás de nuestra parte. La preocupación de Micaela era que la gente que esta con ellos se desanimen y regresen a sus pueblos, también intenta captar la atención de Túpac Amaru insistiendo que deben seguir firmes y efectivos porque también de sus acciones depende el destino de sus hijos.

Desde la perspectiva de la historiadora Claudia Luna, Micaela fue la principal colabora de Túpac Amaru II. Señala que "En cuanto a Micaela Bastidas, esposa y madre de los hijos de Túpac Amaru, fue su principal colaboradora, componiendo la élite que dirigió el movimiento. Ejerció varios roles: articuladora política de la retaguardia de la insurrección, responsable de mantener las tropas rebeldes con géneros y armas, dirigirlas cuando fue necesario, garantizar la lealtad de la gente al movimiento, ejercer roles de jueza frente a los desórdenes o insubordinaciones (Luna, 2015, p.56). Los historiadores como Sara Guardia, Montiel, Sumi coinciden en que Micaela Bastidas fue una gran líder y estratega de la rebelión y que en esa tarea sus hijos lucharon activamente.

Desde la postura de Francesca Gargallo valiéndose de los documentos conservados en el Archivo Histórico de Sevilla considera que Micaela tuvo un papel importante en la dirección técnico-administrativa del movimiento rebelde, resulta que toda la complicada vida de la retaguardia indígena y de los abastecimientos de la campaña estuvo a su cargo. Se consideraba la lugarteniente más inmediata y, en ocasiones, la inspiradora de la lucha de su marido. También fue la inspiración para sus hijos, su familia y las mujeres de los pueblos cusqueños.

\section{Micaela Bastidas, desde la perspectiva de las autoridades española}

Las mujeres se incorporaron al proceso emancipatorio e independentista por las opresiones y abusos que suscitaban en la esfera pública, como el abuso de los corregidores, en los obrajes 
e incremento de tributos. Scarlett determinó el carácter y la composición social de las revueltas anti fiscales en el Cusco en la década de 1770 a 1780.

En Quechualla se alzaron contra el corregidor por repartos excesivos en 1771, en Urubamba se alzaron contra el corregidor Don Pedro Lefedal y Melo por abusos en los repartos en 1777, en, en Chumbivilcas matan a su corregidor 1776. Scarlett (como se citó en Angles, 2004). Todos estos estos pueblos eran aledaños, Cusco comprendía 14 provincias y 133 curatos y era común entra las familias la disconformidad y el sentimiento de injusticia por parte de las autoridades.

Para los peninsulares a quienes les llegó la noticia del protagonismo y las capacidades de Micaela debió ser una sorpresa, porque muchos eran provenientes de España borbónica, cuya imagen de una mujer era pasiva, enfocada en las tareas domésticas, antes sus ojos se presentaban mujeres valientes que lucharon por la justicia de sus pueblos, la noticia también debió correr en España y entre sus colonias.

Como representa Ana Belén García López a las mujeres españolas pasivas antes de 1808, de seguro que los españoles también llegaron con esa imagen presentativa de una mujer europea, en su trabajo la participación de las mujeres en la independencia Belén (2011) señala en 1812, desde varios diarios insurgentes de la Nueva España se solicita a las mujeres que no se casen con españoles y en el supuesto de que lo hagan se les insta a que condicionen el matrimonio al paso de aquellos al bando insurgente. Se les pide también que eduquen a sus hijos a favor de la causa independentista. En el caso de las mujeres casadas con españoles se les sugiere que se conviertan en espías a favor de la causa insurgente $(P, 36)$. Para las autoridades españolas el rol de género se limitaba al matrimonio y la maternidad.

Por otro lado, Eva Valero Juan cuestiona a las autoridades que se concentraron en el poder, de haber relegado a las mujeres de la esfera pública, de aquellas mujeres que salieron del silencio demostrado su participación en la causa independentista para luego haber sido retomado al espacio público como amantes y recluidas en sus hogares y conventos. Valero (2009) señala las mujeres sirvieron muy activamente a la causa independentista, pero fueron devueltos a la esfera de exclusión social -del poder y del saber- que habían ocupado durante los siglos del coloniaje. En el caso de las mujeres, fueron nuevamente recluidas en sus hogares o en los conventos [...], cuando consiguieron salir del silencio fue para ser recuperadas como la amante del libertador Bolívar -Manuela Sáenz-, la esposa del guerrillero Manuel Padilla -Juana Azurduy-, la mujer de Túpac Amaru -Micaela Bastidas [...] la participación de la mujer en la vida social y política tradición que el sistema colonial había tratado de abolir hasta los extremos más vejatorios para la mujer indígena, víctima de todo tipo de abusos (p.70).

Micaela Bastidas es un ejemplo de la mujer que representaba a tantas mujeres valientes que luchan contra la opresión española, y que así se hizo visible en su contexto, pero el concentrado poder político, económico y social de las autoridades borraron por mucho tiempo "la visibilidad de una mujer valiente", para convertirla en el fantasma de sus hogares. 
Micaela Bastidas quedó al frente de la parte administrativa y política de Tungasuca. Es en este período en el que su presencia empezó a perfilarse de manera definitiva: imparte órdenes, otorga salvoconductos, lanza edictos, dispone expediciones para reclutar gente y envía cartas a los caciques. Como se evidencia en la siguiente cita:

"Todos los guardias españoles e indios, y espías puestos por orden de mi marido Don José Gabriel Tupac Amaru, darán paso franco a los que con este pase fueren, sin hacerles el más perjuicio; pena al que contraviniere esta mi orden del castigo que corresponde, y del mismo modo cuando regresen de la ciudad del Cusco para sus lugares. Tungasuca, noviembre $27 \mathrm{de} 178 \mathrm{o}$. Doña Micaela Bastidas" (Guardia, 2015, p.8).

Los españoles cuestionaron el rol de Micaela le tildaron de despiada, su nombre era común entre las autoridades, por su carácter desafiante hasta en más de una ocasión habrá recibido muchos calificativos e insultos, como refiere Guardia (2015) "fue calificada de cruel y odiada por los españoles” (p.93).

Por otro lado, Eva Juan Valero Doctora en Filología Hispánica por la Universidad de Alicante y profesora de Literatura Hispanoamericana valiéndose de algunas crónicas del momento considera que veían a Micaela como superior por la valentía con la que se desempeñaba sus cargos.

También Valero (2009), señala, retrataron a Micaela Bastidas como la figura más valiente y audaz que el propio Tupac Amaru, forjando una imagen de superioridad que confirma la correspondencia mantenida por la pareja durante el transcurso del levantamiento. En aquellas cartas, la Bastidas aparece como principal estratega para la toma del Cuzco, ejerciendo tareas políticas, militares y administrativas, e incluso en determinados momentos la jefatura interna del movimiento (p. 66).

La apreciación que tenían los españoles sobre Micaela eran despectivos, y era más que obvio porque Micaela no podía mostrarse amable "estaba luchando contra ellos", por otro lado de haberla visto como superior, es porque reconocían en ella destrezas que podía desempeñar de manera efectiva.

Micaela desafío la mirada de los españoles "mujeres pasivas", Micaela fue una de las tantas mujeres de su contexto que rompió ese esquema convirtiéndola en "sujeto activo".

Las acciones de Micaela fueron muy trascendentales, en su afán de luchar por la justificia, desencadenó un conjunto de actitudes y emociones que por algunos era reflejos de constancia y valentía y para otra arrogancia. El papel que desempeñó doña Micaela Bastidas Puyucawua tiene capital importancia para conocer la rebelión de Tinta. Puede asegurarse que, desde el primer momento, ella fue el principal consejero de Túpac Amaru, junto al rumoreado Consejo de los cinco. $\mathrm{Y}$ aunque el caudillo actúo mediante decisiones propias, por sus ideas e iniciativas parece la figura de esta enérgica y prócer mujer con los caracteres de un personaje de valor innegable. Varios testigos en el juicio afirmarían que ella fue más cruel, rebelde, arrogante y despótica que Túpac Amaru, siendo en consecuencia más temida que jefe ninguno 
(Valcárcel, 1973, p.95). Sus emociones y rasgos de su personalidad se ven reflejadas en las tareas que ella realizaba.

La postura de Valcárcel se respalda en la declaración de Don Francisco Molina en la ciudad de Cuzco a veinte y un días del mes de abril de 1781, ante el Señor Don Benito de la Mata Linares, declaró que "Micaela daba ordenes por escrito y de palabra con más rigor que Túpac Amaru para que estén a devoción de su marido, hacienda correr la palabra de que si no obedecían o iban contra el rebelde experimentarían suplicio y perdida de sus bienes”. En este fragmento de una parte de la declaración se evidencia que le reconocen a Micaela como una mujer que conocía las estrategias y las formas para unir a los hombres a las fuerzas patrióticas, muchos desistieron no por temor a Micaela sino porque también vivían un conflicto interno y por temor a la represalia no estaban dispuestos a perder su vida por no declarar.

\section{Micaela Bastidas, desde la perspectiva del ejército patriótico}

Los compatriotas que estuvieron más tiempo con ella, admiraban su coraje y valentía, Micaela representaba la esperanza de miles de madres y hombres que se habían sumado a la lucha contra la opresión.

Sumando las interpretaciones de las cartas que mandó escribir, Guardia (como se citó en Valero, 2009). Señala que "son cartas destinadas a informarle cuestiones puntuales; solicitudes de justicia a través de las cuales se advierte que tenía autoridad suficiente para dirimir, juzgar y sentenciar. En ellas la llaman: "muy señora mía”, "muy amada hermanita mía”, "amantísima y muy señora mía”, inclusive "señora gobernadora (p.9). Con respeto, temor o cariño muchos se sentían identificados con Micaela.

En esa misma línea Pagés (2013) señala que Micaela era una mujer de coraje y actitud, pues se encargó de la parte administrativa y política de la insurrección. Como "mama chic" madre de los pobres (es decir, de los indios) se la ha asociado a las reivindicaciones indígenas, pero al mismo tiempo a la nación peruana (p.184). En Micaela muchos y muchas guardaban la esperanza de un cambio, la población que compartió y vio de cerca y sintió de lejos su lucha inalcanzable se encargó de que sea visible para los suyos.

De acuerdo a Szeminki (1993). "Fernando Guirpe y Agustin Aucagualpa, dos funcionarios de Pirque (...) informan a Micaela Bastidas acerca de los acontecimientos y el cumplimiento de las órdenes, pidiéndole reorganice la administración de la aldea [...] otro funcionario rebelde Melchor Castelo escribe a Micaela Bastidas acerca de los acontecimientos y del cumplimiento de las órdenes diciendo que los caciques de todos los once ayllus cumplieron con sus órdenes, salvo uno porque se hallaba "en compañía del señor gobernador" es decir el inca. Esta carta termina con las siguientes palabras. "Dios nuestro señor guarde su apreciable vida para alivio y descanso de sus compatriotas" (p. 281). 
Como parte de las responsabilidades que asumía Micaela, a ella le hacían saber de sus logros y necesidades, "no se ordena, por ordenar", que hayan cumplido once ayllus sus órdenes es sinónimo de efectividad y liderazgo. En la nota al señalar que el señor le ilumine para el alivio de sus compatriotas, es porque cada día esperaban un sentimiento de tranquilidad, si esa era expresión de los compatriotas, imaginemos el alivio que sentían sus hijos y Micaela al ver que se terminó el día y saber que sus hijos estaban con "vida".

Micaela el 27 de noviembre desde Velille le dice: "Acabo de recibir carta de Layo en la que me dan la noticia de que vienen soldados de Lampa y Azángaro; y así, precisa mucho que mandes poner toda la gente en el cerro de Chullocani hasta que yo regrese de este Velille, que será el viernes, porque siempre pasaré a dicho pueblo de Layo a poner atajo en el tránsito" También será preciso que Don Juan Antonio Figueroa lleve todos los cañones a dicho cerro (Guardia, 2019. p. 23). Micaela era muy explícita cuando proponía, sugería u ordenaba.

En dos cartas reveladoras de 1780 publicado por Perú Bicentenario señalan que la esposa del líder rebelde Túpac Amaru II dejó prueba de sus radicales decisiones ante los abusos de la monarquía española contra los antiguos peruanos en dicha carta, ella como patriota se expresó de la siguiente manera: "Tenemos a nuestro favor las provincias de Urubamba, Paucartambo, las ocho parroquias, la de Quispicanchi, Paruro, Tinta, Lampa, Azángaro, Paucarcoclla, Carabaya, la ciudad de Chucuito y otras con innumerable gente; y estando en este estado, es preciso que salgan los ladrones o paguen con sus vidas. De la legalidad de usted espero no dé lugar a nada, sino antes acudir a un tan buen fin, de que resulta un beneficio común a este Reino. Dios guarde a usted muchos años. Tungasuca, diciembre 15 de 1780 . De usted, su segura servidora, doña Micaela Bastidas" (Sifuentes 2020). Era una forma de exponer con mucho orgullo las cosas que lograban para que la personas se sumen y no desvanezcan.

\section{Micaela juntos a sus hijos hasta el final de sus días.}

Es muy probable que las estrategias que planteaba Micaela eran más certeras, que de haber seguido sus sugerencias otro hubiera sido el resultado, para Carlos Daniel la estrategia de Micaela, pudo haber cambiado el curso de la historia, porque considera que para Micaela Cusco era lo primero que los demás pueblos podían esperar, sin embargo Túpac Amaru pasó al sur y persistió en su avance pensando que tendría mejores resultados Valcárcel (1995), señala que a partir que quedó como jefe interino doña Micaela, su incansable actividad, para resolver problemas administrativos [...] , impulsar propaganda, incrementar la tropa, reunir informes sobre las provincias amigas y contrarias, prueban lo acertado de su elección para un cargo con tanta responsabilidad y de tan devota lealtad (p.97). El cargo que tuvo es admirable, porque trataba de cumplir con mucha responsabilidad, sacrificando una vida en familia.

Micaela Bastidas sabía que existía personas leales, y aunque ella y su esposo no estaban dispuestos a revelar sus estrategias, muchas personas no tenían la misma valentía y 
convicción, varios terminaron rindiéndose ante la presión y tortura de los españoles, optaron por traicionar y revelar los secretos de la rebelión. Menciona Guardia (2015) Micaela Bastidas recibió un mensaje secreto anunciándole la detención y partió con sus hijos y varios familiares por el camino de Livitaca donde fue emboscada, traicionada también por Ventura Landaeta [...] el Visitador previno a Tupac Amaru y a Micaela Bastidas que se despidiesen de sus hijos porque no los volverían a ver nunca más. Era Domingo de Ramos de la Semana Santa del 16 de abril de 1781 (p. 31). Imaginamos que los sentimientos de madre, padre e hijos fue desgarrador, pero es una prueba más del conflicto que sentía entre ser madre y estar luchando en contra del dominio de los españoles.

Del mismo modo describe el contexto Bonilla (1971) Túpac Amaru trató de evitar su captura, cruzando a nado el torrentoso río Combapata. Buscaba refugio en el cercano pueblo de Langui, cuando ese mismo 6 de abril fue vendido por un capitán de sus propio ejército, el mestizo cusqueño Francisco Santa Cruz [...] mientras Micaela Bastidas acompañaba de sus dos menores hijos Hipólito y Fernando, y de su hermano Antonio Bastidas, de la cacica de Acos, la valerosa Tomasa Tito Condemayta y de otras personal de su guardia personal, eran apresados en el camino que va de Titicaca a las alturas del Collao traicionados también por un tal Ventura Landaeta (p.169). En los últimos días donde se agitaba más la situación Micaela estaba más cerca de sus hijos en especial de Fernando que era el menor.

La situación empeoró cuando Tupac Amaru fue capturado pues ella y su familia tenían que asumir más responsabilidades y retos, además Micaela representó las esperanzas y resentimientos de un espíritu de venganza, aspectos que los mantuvo unidos para alistar el centro rebelde en Azángaro. Como señala Sminski (1993). El centro rebelde de Azángaro se formó después de la captura de Thupa Amaro y de la toma de Tungasuca por parte de las tropas españolas. La comandancia como jefe de la insurrección recaía en inca, Diego Cristóbal Thupa Amaru Inca, logrando que Azángaro se convierta en su sede, por otro lado, Mariano Thupa Amaro, hijo del inca unidos con aquellos que lograron escapar de la derrota de Tinta, cuando cayó prisionero el 5 de abril de 1781 .

Cuando ella también fue tomada por los españoles se mostró valiente y retadora ante los españoles, en la carta interpretada por Jorge Cornejo se puede apreciar la valentía de Micaela en el interrogatorio. Señala Cornejo (1954) En las declaraciones que se arrancaron a doña Micaela Bastidas - trasncritas en "Sangre Andina" por los conocidos procedimiento de torturas y vejámenes, dice la coya sublime: “[...] Manifestosele un lienzo en esta retratado su marido, a caballo, con insignias reales, para que diga quién pintó, quién dio este pensamiento, con qué fin lo retrataron; y dice: ser cierto el retrato de su marido, con la insignias reales, que lo pintó un zambo Antonio, que si lo matan quedaría este retrato para memoria de los Tupac Amaru, que el pensamiento fue de su marido, y que el fin era para que lo viesen en las provincias, y después enviar a España. ¿Leído todo esto cabe dudar todavía? Salve un capricho y con capricho no se construye, ni merece discutirse nada (407). Al final por todas las acciones que realizaron la familia Tupac Amaru no solo quedó para la memoria de la familia sino para la memoria del mundo. 
La rebelión fue muy comentada en el contexto mundial solo a manera de ejemplo Losif Grigulevich señala que en la unión soviética admiran la insurrección de Túpac Amaru II, considerando que sienten simpatía hacia el jefe indio.

Los españoles no satisfechos con haber capturado a los líderes, se esmeraron por encontrar al resto de la familia al respecto Zeminski (1993) refiere, Areche en un documento lleno de dignidad le contestó [...] el 6 de abril "la mujer del rebelde, sus dos hijos, otros cinco de su familia experimentaron la misma suerte de aquél pues huyendo por el camino de Livitaca para salir al de la paz, fueron arrestado todos, con doce cargas de plata sellada, por la tropa de la quinta columna al mando de don Francisco Laysequilla y el coronel Don Domingo Marnara, solo falta de esa maldita raza aprisionar a Diego Túpac Amaru, hermano del traído...” (p. 197). Con ello se iba marcando la parte más difícil para la familia y los insurrectos.

A pesar de lo difícil que fue para Micaela Bastidas dividir entre el amor por sus hijos y su pueblo luchó inalcanzablemente hasta ver morir a sus hijos y sus hijos ver morir a su madre. Que tan doloroso habrá sido para Micaela, madre, y para todas las madres que vivieron en ese contexto, como señala Montiel Edgar. El relato histórico no sólo ha silenciado a mujeres (adultas) sino también a niñas y niños que fueron víctimas de castigos y condiciones severas de detención, no teniendo ninguna condena que pagar. La familia Tito fue prácticamente decimada en el agónico viaje a Cádiz: murieron las niñas Juliana Tito, María Tito, Feliciana Tito, y el niño Gregorio Tito. De los niños se salvaron Mariano Tito y Miguel Tito. Se salvó también Fernando Túpac Amaru, el menor de la familia. Esta es la historia olvidada de los niños mártires del Perú y América Como si, por definición, las mujeres, niñas y niños no calificaran epistemológicamente para el relato histórico (p.46).

De la cita resaltamos que se salvó el menor de los hijos de Micaela y Túpac Amaru, Fernando Túpac Amaru, "salvarse" que significa para el autor haberse quedado con vida, pero la forma en como fue obligado a observar la tortura de su madre y el crudo viaje a España, quizá en el algún momento Fernando (hijo) pensó que mejor hubiera sido morir.

En las siguientes líneas se detalla el sufrimiento de Fernando de ver la crueldad con la que ejecutan a su mamá y a sus familiares. Como refiere Gargallo (2015) El niño quiere volver la cabeza, pero los soldados le obligan a mirar. Fernando ve cómo el verdugo arranca la lengua de su hermano Hipólito y lo empuja desde la escalera de la horca. El verdugo cuelga también a dos de los tíos de Fernando y después al esclavo Antonio Oblitas, que había pintado el retrato de Túpac Amaru, y a golpes de hacha lo corta en pedazos; y Fernando ve. [...]Entonces sube al tablado Micaela Bastidas y Fernando ve menos. Se le nublan los ojos mientras el verdugo busca la lengua de Micaela, y una cortina de lágrimas tapa los ojos del niño cuando sientan a su madre para culminar el suplicio: el torno no consigue ahogar el fino cuello y es preciso que, echándole lazos al pescuezo, tirando de una y otra parte y dándole patadas en el estómago y pechos, la acaben de matar (P.123). 
Portal a través de su poema visibiliza la crudeza de su hijo Fernando el último de sus hijos de Micaela, "En ti lucharon todas las mujeres, todas las mujeres ultrajadas, las muchachas heridas" (Portal, 2010, p. 291). poema "Palabras a Micaela Bastidas". Que terrible y traumante escena para el pobre niño Fernando, que con apenas doce años tuvo que ser testigo de tanta crueldad, Micaela era como un espejo en donde miles de mujeres se veían.

Walker también criticó las actitudes de los españoles considerando que se excedieron al castigar a la madre y a su hijo menor, Fernando Túpac Amaru, que siendo apenas un niño de nomás de doce años fue obligado a presenciar bárbaro ajusticiamiento de sus tíos, de su hermano mayor Hipólito y de sus padres José Gabriel Túpac Amaru y Micaela Bastidas. Markham (como se citó en Walker, 2015):

al ver a su infortunado padre venciendo la fortaleza de su cuerpo al brutal esfuerzo de los caballos que tiraban de brazos y piernas, sin poder destroncarle..., lanzó un grito que impresionó hondamente a la multitud despavorida que contempla la escena, grito que fue la sentencia de muerte de la dominación española en América. [...] Fernando sufriría un largo destierro abrumado por la nostalgia y la enfermedad. Hasta en 1798 en que falleció, sería un hipocondriaco aplastado por el recuerdo y la impotencia (p.169).

De seguro que el grito de Fernando estremeció el cuerpo y alma de los que presenciaron tanta crueldad, el grito que destrozó el corazón de muchas madres, finalmente los españoles no solo mutilaron el cuerpo de Micaela, sino que también mutilaron la voz de muchas mujeres y niños.

\section{DISCUSIONES}

El sentimiento maternal de Micaela Bastidas motivó su incorporación y protagonismo en el proceso de rebelión, al haber tenido una familia unida, se vio afectado por las injusticias de las autoridades hispánicas. La hipótesis se respalda en la perspectiva de la historiadora Scarlett O’ Phelan quien valiéndose de la interpretación de las petacas que fue compartido por Edgar Montiel, detallaron los elementos personales que encontraron de la familia, entre ellos la obra de Garcilaso, señalando que formó parte de la formación intelectual de sus hijos, así mismo Sara Beatriz resalta su rol maternal poniendo énfasis en que Micaela y Túpac Amaru fueron padres que se preocupaban por la educación de sus hijos, en en ellos incentivaron el sentimiento de justicia y libertad, además para dar crédito a ambas posturas, en las cartas que dictó Micaela a sus escribiente se evidencia la participación activa de sus dos hijos Hipólito y Mariano en la rebelión.

Micaela Bastidas no solo protagonizó la rebelión por su sentimiento maternal, por lo contrario, fijó su mirada en la búsqueda de libertad, con decisión propia y acciones autónomas, se sobrepuso su rol de heroína, por encima de su rol de madre, a las pruebas se remite de que pudiendo haber revelado a sus cómplices a cambio de salvar su vida, prefirió quedarse sin lengua y sin vida. Esta hipótesis no se ha puesto en tela de juicio. En los trabajos

Revista Revoluciones -102- Vol. 3, Nº 5 (2021), pp. 88-105 
de los autores anteriormente mencionados se exalta el rol político y administrativo de Micaela contra la opresión militar española, pero no se detienen a profundizar ambos roles.

Micaela rompió el esquema de mujer pasiva e invisible del siglo XVIII, era admirada y respetada por las tropas compatriotas, también las tropas hispánicas reconocieron su papel determinante en el contexto de la rebelión. Como se evidencia en la declaración de Don Francisco Molina en la ciudad de Cuzco a veinte y un días del mes de abril de 1781, ante el Señor Don Benito de la Mata Linares, declaró que "Micaela daba ordenes por escrito y de palabra con más rigor que Túpac Amaru para que estén a devoción de su marido, hacienda correr la palabra de que si no obedecían o iban contra el rebelde experimentarían suplicio y perdida de sus bienes". En este fragmento de una parte de la declaración se evidencia que le reconocen a Micaela como una mujer que conocía las estrategias y las formas para unir a los hombres a las fuerzas patrióticas, muchos desistieron no por temor a Micaela sino porque también vivían un conflicto interno y por temor a la represalian no estaban dispuestos a perder su vida por no declarar.

Las autoridades peninsulares no valoraron su rol en el espacio público ni su sol de madre, porque hasta sus hijos pagaron la condena cruel de las autoridades, pues temían que los niños que estaban en plena formación adopten las actitudes de los "rebeldes", muchos niños fueron testigos de crueles castigos y pese a ello las mujeres y niños quedaron atrapados en el olvido de la historia, esta hipótesis del conflicto entre su amor propio, amor de sus hijos, y amor por su patria se respalda la postura de Edgar Montiel quien considera que las mujeres adultas, niñas y niños pagaron una condena, anotó sobre la familia Tito que fue decimada en el agonía del viaje a Cádiz, en donde murieron las niñas Juliana Tito, María Tito, Feliciana Tito, y el niño Gregorio Tito. De los niños se salvaron Mariano Tito y Miguel Tito, Túpac Amaru, el menor de la familia, Montiel critica que ellos pese a ser los mártires epistemológicamente no calificaron para el relato histórico.

El artículo expone el conflicto de roles que Micaela Bastidas tuvo que lidiar como madre y heroína, en un escenario en el que fue sentenciada a muerte por haber traspasado la línea del rol pasivo a un rol activo.

Una posible limitación del artículo es que no presenta manuscritos de su vida familiar, los conflictos más se explican desde la participación de ella y sus hijos en el escenario de la rebelión, asimismo la desproporción de ejemplos concretos y perspectivas que cuestionan que afinan el perfil de una mujer despiadada contra las tropas realistas o contra los indígenas que no querían unirse a las fuerzas patrióticas.

La investigación deja abierta a futuras investigaciones que desean profundizar el conflicto de roles de Micaela Bastidas antes de la ejecución del corregidor Antonio Arriaga, no solo de Micaela sino de más mujeres miembros de su familia y de los pueblos circundantes, y de otras regiones del Perú, muchas salieron a la luz, pero los estudios son limitados apenas se sabe sus nombres. 


\section{CONCLUSIONES}

Cuantas veces Micaela Bastidas habrá intentado equilibrar su sentimiento maternal y su heroísmo, una inflexión que podemos afirmar que llegó a su fin cuando decidió no delatar a los que apoyaron a la causa, aun cuando sabía que eso le pudo haber salvado la vida, sin embargo, a costa del amor por sus hijos, su esposo y su familia entregó su vida sin comprometer a los suyos.

Micaela traspasó las fronteras de su espacio privado a un espacio público, aunque esos roles no fueron compatibles, destacó su protagonismo en todo el proceso de rebelión, planificando, ordenando, enviando salvoconductos, administrando, aprovisionando a las tropas, juntando hombres a la causa patriótica entre otros, rompiendo el esquema de una mujer pasiva ante los ojos de las autoridades hispánicas y las tropas realistas.

Su familia y las tropas compatriotas respetaron sur rol en el espacio público, pero las tropas realistas sentenciaron ambos roles, escarmentado a Micaela y otras mujeres de la manera más despiadada y lo más inaceptable sin importar las edades también sus hijos pagaron el precio de las mujeres que lucharon por la justicia de su pueblo, un claro ejemplo es el único sobre viviente de los hijos de Túpac Amaru y Micaela Bastidas, Fernando quien fue obligado a ver las atrocidades de la ejecución de sus padres, sus hermanos y le obligaron a emprender el viaje hacia el infierno "Cádiz" en donde murió a corta edad.

\section{REFERENCIAS BIBLIOGRÁFICAS}

Angles, V. (2013). José Gabriel Túpac Amaru Ediciones Industrial, gráfica S.A

Barrionuevo, A. (1976). Habla Micaela. Lima, Perú. Ediciones Iberia. S.A.

Berg, M. (2013). Mujeres y Emancipación de la América Latina y en el Caribe en los siglos XIX a XX. https://books.openedition.org/ledizioni/326?lang=es. ISBN: 9788867053612. DOI: https://doi.org/10.400o/books.ledizioni.326.

Garay, J. (2018). El pensamiento de Simone de Beauvoir: la mujer como sujeto histórico y filosófico. Argentina: CLASCO.

Bonilla, J. (1971). La revolución de Túpac Amaru. Lima, Perú. Ediciones nuevo mundo.

Cornejo, B. (1954). El sentido libertario de la revolución de Túpac Amaru página $\mathrm{N}^{\circ} 5$. Cuzco. Empresa Editorial Cuzco S.A. "El Comercio".

Guardia, S., Montiel, E., Luna, C., Arango, F. Micaela Bastidas [conferencia]. Simposio Internacional Las Mujeres en la Formación de los Estados Nacionales en América Latina y El Caribe. Micaela Bastidas. Lima, Perú. https://www.cemhal.org/Libro_Micaela_Bastidas.pdf

Grigulevich, L. (1988). Luchadores por la Libertad de América Latina. Moscú, Rusia. Editorial Progreso.

Ideas feministas de nuestra América. (2011). Micaela Bastidas Puyucawa, Jefa de la retaguardia india de la rebelión de Tupac Amaru, Carta, pasaportes y salvoconducto con su firma. https://ideasfem.wordpress.com/textos/a/ao8/ 
Huerto, H. (2017). Nueva Colección Documental de la Independencia del Perú. La rebelión de Túpac Amaru II [Vol. 1]. Lima: Universidad Peruana de Ciencias Aplicadas.

Luna, C. (Edic. Sara Beatriz Guardia). (2019). Micaela Bastidas. Lima Perú.

Lewin,

B.

(1997).

Túpac

Amaru. https://bibliotecavirtual.unl.edu.ar:8443/bitstream/handle/11185/3825/RUo36_o6_ Ao04.pdf?sequence $=1 \&$ isAllowed $=\mathrm{y}$

Montiel, E. (Edic. Sara Beatriz Guardia). (2019). Micaela Bastidas. Lima Perú

Pagués, G. (2013). Mujeres entre Mundos. Discursos tópicos y realidades de género en América Latina (Perú, siglo XVIII). [tesis doctoral, Universidad Autónoma de Barcelona]. https://dialnet.unirioja.es/servlet/tesis?codigo $=117481$

Szeminski, J. (1993). La utopía tupamarista. Lima, Perú. Pontifica La utopía tupamarista.

Sumi, A. (2017). El Liderazgo de Micaela Bastidas Puyucahua. Apurímac, Perú: Primera edición. Gato viejo grupo editorial.

O'phelan S. (1995). Por el Rey, religión y la patria las juntas de gobierno de 1809 en la Paz y Quito. Bull Inst. Fre. Et. An http://www.ifea.org.pe/libreria/bulletin/1988/pdf/61.pdf

Valero, J. (2009). De Micaela a Magna Portales. Recuperaciones crítico - literarias de las independentistas del Perú. América sin nombre, 64-72 (13 -14). pp. 64-72 ISSN 15773442.

Walker, Ch. (2016). La rebelión de Túpac Amaru. Apuntes. Volumen 3 ( $\left.\mathrm{N}^{\circ} 78\right)$. Lima, Perú. Edición IEP (Estudios históricos Peruanos).http://www.scielo.org.pe/scielo.php?script=sci_arttext\&pid=So25218652016000100010 org/10.21678/0252-1865-00430078_05 